\title{
Unresolved basic issues in hepatology
}

Basic research and comparative human medical advances during the last decades and centuries have significantly improved diagnostic and treatment modalities in Hepatology. However, the evolution of this area has sparked not only scientific and clinical benefits but also controversies. The focused series "Unresolved Basic Issues in Hepatology" contains 13 reviews from leading experts from Australia, Austria, Canada, China, France, Germany, India, UK and USA highlighting current perspectives on hot and often controversial discussed topics in the field of Hepatology (Figure 1).

In their article "Revisiting hemochromatosis: genetic vs. phenotypic manifestations", Anderson and Bardou-Jacquet report about the high phenotypic variability in hereditary hemochromatosis that can be largely explained by a range of environmental, genetic and physiological factors. They strengthen the point that variations in penetrance between individuals might be due to the fact that some genes involved in the pathogenesis of iron homeostasis disorders are still not know yet and that both co-morbidities and genetic polymorphisms that do not affect iron levels per se could influence or determine the propensity of the disease.

The review "Autoimmune hepatitis: is histology conclusive?" by Beer and Dienes critically discuss the diagnostic value of liver biopsy in the diagnosis and management of autoimmune hepatitis. The authors provide some clues on the histological difference between clinical subtypes of autoimmune hepatitis showing that a definitive diagnosis of autoimmune hepatitis is not possible by histology alone and should be better based on combined criteria including the presence of autoantibodies, immunoglobulin $\mathrm{G}$ elevations, and graded histopathology.

Cai and Boyer discuss "The role of bile acids in cholestatic liver injury" focusing on their direct effects on hepatocytes, cholangiocytes, stellate cells and immune cells. From their contribution it became clear that despite the fundamental insights in the pathogenesis of cholestatic liver injury, important mechanistic details on the effects of bile acids on specific liver cells are still not understood.

Ding and colleagues highlight the current knowledge on "Exosomes as therapeutic vehicles in liver diseases". They describe the role of exosomes and their cargo as potential therapeutic tools to treat or to alleviate liver injury caused by various factors. As the authors discuss, there are still many problems to be solved before the wealth of encouraging findings obtained with these membrane-bound extracellular vesicles in preclinical studies can be applied clinically.

In the review "It's all about the spaces between cells: Role of extracellular matrix in liver fibrosis" Khurana and colleagues critically discuss the advances in the understanding of the physiological role of factors contributing to extracellular matrix homeostasis, turnover and impairment. Particularly, it is discussed how the knowledge of individual mediators can be harnessed for the therapy of hepatic fibrosis.

In their article "Liver failure-future challenges and remaining questions" Lemmer and colleagues describe controversial aspects in the classification of liver failure. They propose that it is necessary to differentiate three types of liver failure, namely acute liver failure, acute-on-chronic liver failure, and acute-on-liver-cirrhosis that mainly can be discriminated by changes in coagulation factors and inhibitors.

Melnik reviewed molecular mechanisms that may explain dairy-induced hepatocancerogenesis. In his article entitled "Dairy consumption and hepatocellular carcinoma risk" he highlights how abundant constitutes of milk proteins and milk exosomes and their cargo might contribute to the pathogenesis of hepatocellular carcinoma. Based on accumulating evidence from a large number of epidemiological and translational studies, he concluded that several milk products need to be listed as dairyrelated risk factors for hepatocellular carcinoma.

The article "Non-alcoholic fatty liver diseases: current challenges and future directions" written by Roeb provides information about critical issues in the pathogenesis of non-alcoholic fatty liver disease (NAFLD). It summarizes comprehensively the actual knowledge about relevant risk factors and management strategies. In her article she nicely illustrates that key questions related to disease definition, diagnosis, therapy, and long-term management are still only partially answered. In line with this assumption, Rosso and colleagues argued that there is an urgent need to identify better biomarkers for the diagnosis of NAFLD. In their contribution "Diagnostic management of nonalcoholic fatty liver disease: a 


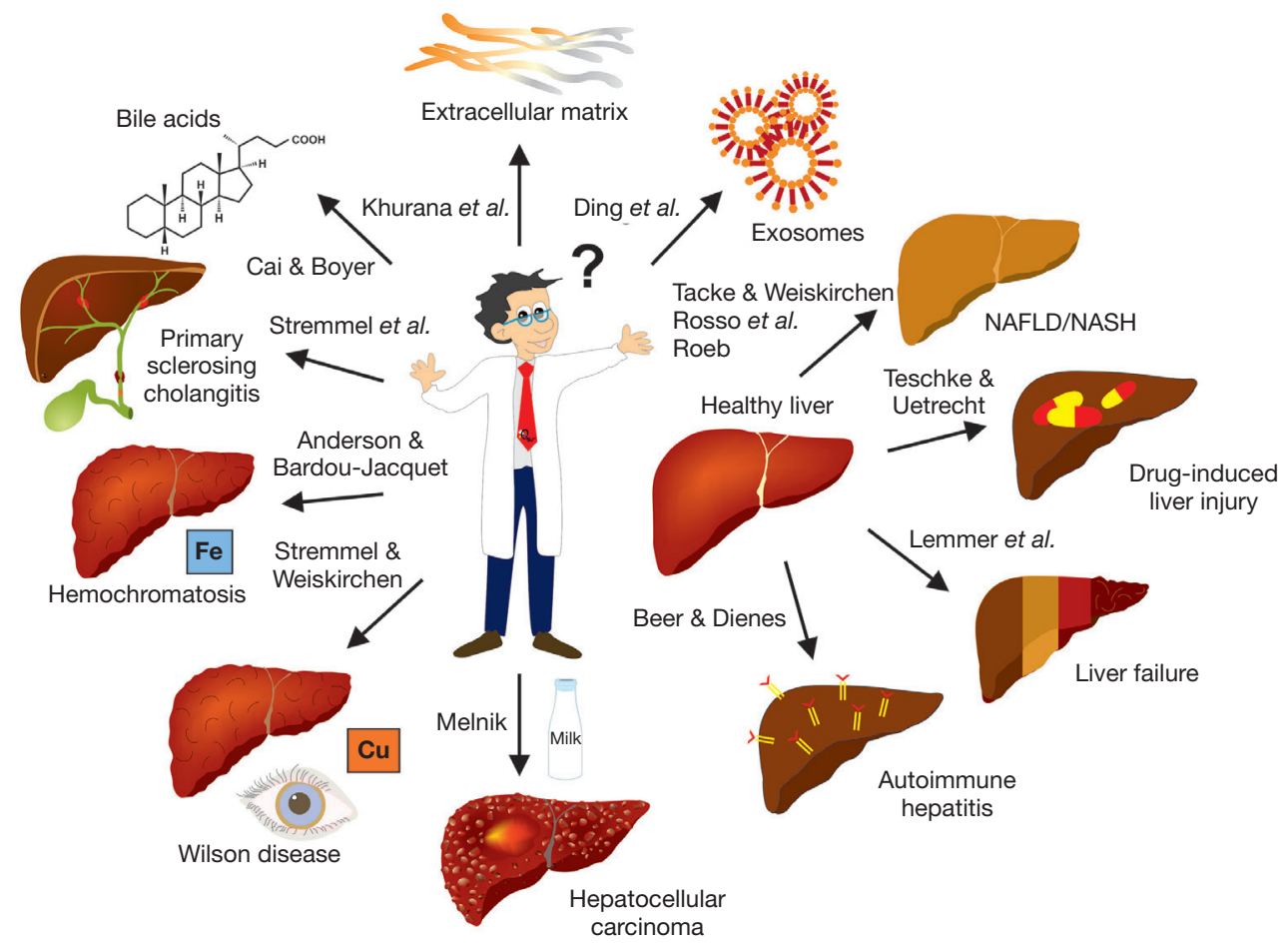

Figure 1 Topics covered in this focused series. The special series "Unresolved Basic Issues in Hepatology" contains 13 review articles written by 27 authors from 9 countries. These contributions discuss new mechanistic concepts and controversial issues in the pathogenesis of liver disease. These articles will be helpful to close potential gaps in understanding aspects of hepatic disease processes and to foster a lively discussion on their diagnostic or management. NAFLD, non-alcoholic fatty liver disease; NASH, non-alcoholic steatohepatitis.

transformational period in the development of diagnostic and predictive tools—a narrative review" they argued that patients would need to be stratified better according to their metabolic, genomic, proteomic, lipidomic, and microbiotic profile to establish a framework with the broader goal of creating predictable disease pathways and personalized treatment strategies. The article "Non-alcoholic fatty liver disease (NAFLD)/non-alcoholic steatohepatitis (NASH)-related liver fibrosis: mechanisms, treatment and prevention" by Tacke and Weiskirchen call attention to the fact that there are several promising drug candidates for effective pharmacological therapy of NAFLD and its consequences (i.e., fibrosis). However, some of these encouraging drugs failed in phase 2 or 3 clinical trials suggesting that combinatorial drug treatment and radical lifestyle changes still hold the greatest clinical prospects.

The article by Teschke and Uetrecht entitled "Mechanism of idiosyncratic drug induced liver injury (DILI): unresolved basic issues" discuss gaps of understanding in the pathogenesis of drug-induced liver injury (DILI). In particular, the authors underline the interaction of immune aspects with gut microbiome and hepatic cytochrome P450 that together contribute to drug metabolism. This article underpins the notion that it is desirable to better elucidate the cascade of events during DILI and that at present it is important to recognize early symptoms of DILI with the aim to discontinue the use of the incriminated drug.

In the article "Therapeutic strategies in Wilson disease: pathophysiology and mode of action" Stremmel and Weiskirchen critically discuss the present therapeutic options in removing excessive copper content in therapy of Wilson disease. They 
mentioned that none of the present therapies applied in Wilson disease have been approved in randomized controlled trials. Based on their argumentation the disease does not necessarily require a depletion of hepatic copper from the organism. It might be fully adequate to turn toxic copper into harmless biological inactive deposits to obtain therapeutic effects.

Another article by Stremmel and coworkers entitled "The neglected biliary mucus and its phosphatidylcholine content: a putative player in pathogenesis of primary cholangitis—a narrative review article" suggests that ulcerative colitis and primary cholangitis are epidemiologically linked and caused by a common pathogenetic background. They provide a logical chain of argumentation in which deficient phosphatidylcholine content in biliary mucus induced by disturbances of the tight junction barrier function is a key in the pathogenesis of both diseases.

We are convinced that the different articles of this focused series are more than just a summary of what has been published as core scientific facts in a particular field. They report about areas of controversy and highlight under-examined aspects of research. In some cases, the authors have challenged fixed theories and spotlight potential future avenues in diagnosis and management of liver diseases.

\section{Acknowledgments}

We cordially thank the experts for their excellent overviews on these timely topics. Moreover, we are very grateful to the editors and staff of Annals of Translational Medicine that helped to arrange a strict review process and enabled reliable correspondence with the authors. In particular, we would like to thank Teresa Lin who at all-time kept track of the status of individual manuscripts. Moreover, we would like to acknowledge the excellent and efficient work of all reviewers who reviewed submission in a constructive, fair and timely manner.

Funding: None.

\section{Footnote}

Provenance and Peer Review: This article was commissioned by the editorial office, Annals of Translational Medicine for the series "Unresolved Basic Issues in Hepatology". The article did not undergo external peer review.

Conflicts of Interest: Both authors have completed the ICMJE uniform disclosure form (available at http://dx.doi.org/10.21037/ atm-20-8208). The series "Unresolved Basic Issues in Hepatology" was commissioned by the editorial office without any funding or sponsorship. Ralf Weiskirchen and Wolfgang Stremmel served as the unpaid Guest Editors of the series. RW serves as an unpaid editorial board member of Annals of Translational Medicine from Aug 2020 to Jul 2022. Dr. RW reports grants from German Research Foundation, outside the submitted work. The authors have no other conflicts of interest to declare.

Ethical Statement: The authors are accountable for all aspects of the work in ensuring that questions related to the accuracy or integrity of any part of the work are appropriately investigated and resolved.

Open Access Statement: This is an Open Access article distributed in accordance with the Creative Commons AttributionNonCommercial-NoDerivs 4.0 International License (CC BY-NC-ND 4.0), which permits the non-commercial replication and distribution of the article with the strict proviso that no changes or edits are made and the original work is properly cited (including links to both the formal publication through the relevant DOI and the license). See: https://creativecommons.org/licenses/by-nc$\mathrm{nd} / 4.0 /$. 


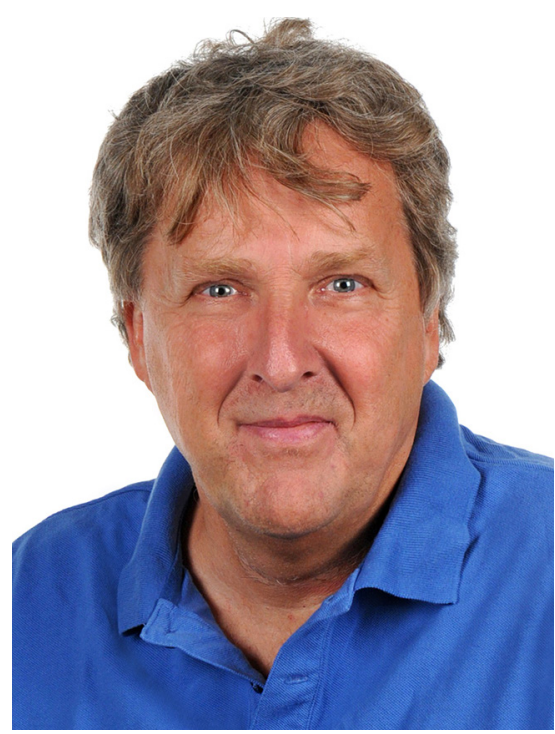

Ralf Weiskirchen

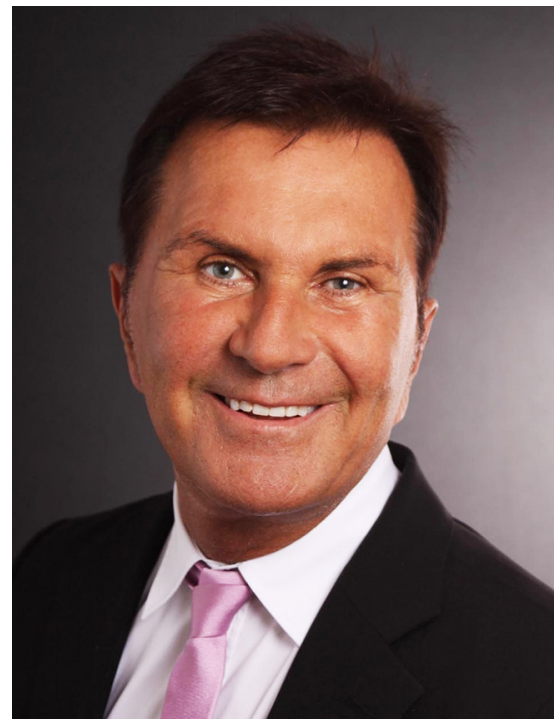

Wolfgang Stremmel

Ralf Weiskirchen^, PhD Institute of Molecular Pathobiochemistry, Experimental Gene Therapy and Clinical Chemistry, RWTH University Hospital Aachen, Aachen, Germany.

(Email: rweiskirchen@ukaachen.de)

Wolfgang Stremmel^, MD

Practice for Gastroenterology, Medical Center Baden-Baden, Baden-Baden, Germany.

(Email: wolfgangstremmel@aol.com)

Submitted Dec 29, 2020. Accepted for publication Jan 14, 2021.

doi: $10.21037 /$ atm-20-8208

View this article at: http://dx.doi.org/10.21037/atm-20-8208

Cite this article as: Weiskirchen $\mathrm{R}$, Stremmel W. Unresolved basic issues in hepatology. Ann Transl Med 2021;9(8):725. doi: 10.21037/atm-20-8208

^ ORCID: Ralf Weiskirchen, 0000-0003-3888-0931; Wolfgang Stremmel, 0000-0002-8545-1753. 